NASA

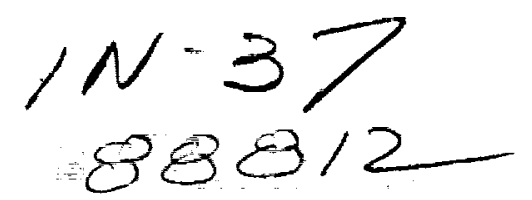

Technical Memorandum 105606

AVSCOM

\title{
Effect of Contact Ratio on Spur Gear Dynamic Load
}

Chuen-Hūei Liou and Hsiang Hsi Lin

Memphis State University

Memphis, Tennessee

and

Fred B. Oswald and Dennis P. Townsend

Lewis Research Center

Cleveland, Ohio

Prepared for the

Sixth International Power Transmission and Gearing Conference sponsored by the American Society of Mechanical Engineers

-.... Phoenix, Arizona, September 13-16, 1992

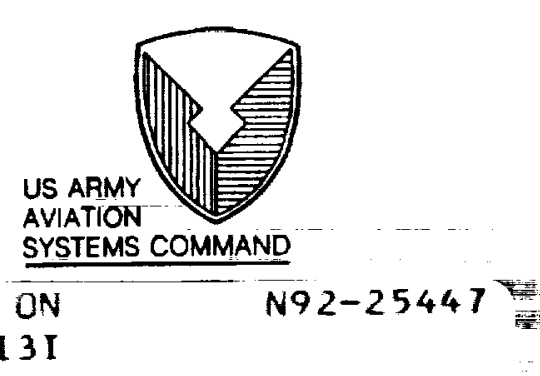



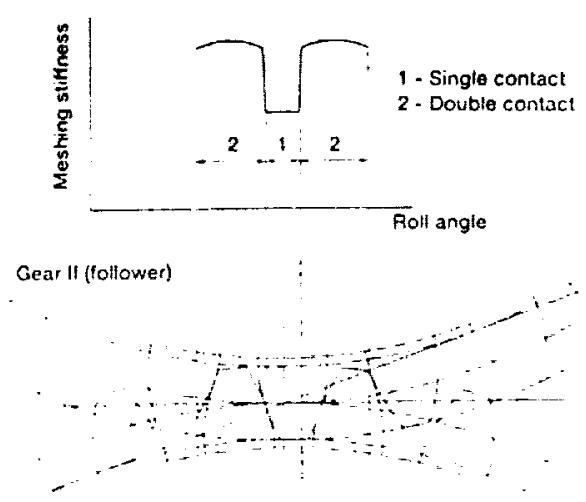

Gear I (driver)

Fig. 1.-Stilfness variation and meshing geometry of lowcontact-fatio gears. Contact ratio, 1.668.

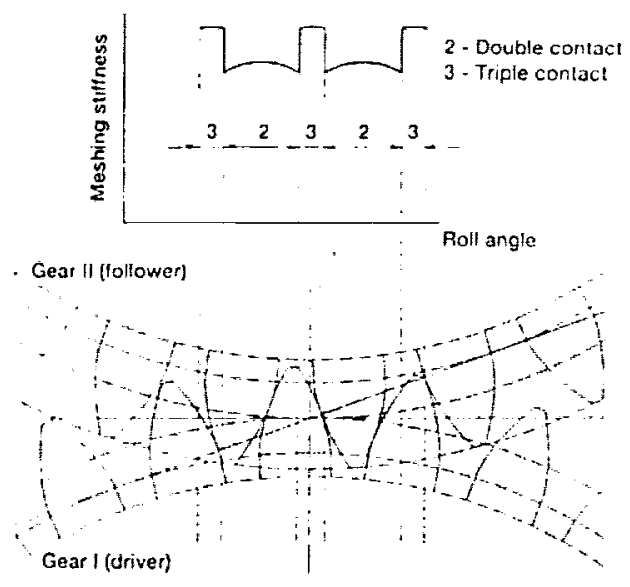

Fig. 2.-Stiffness varialion and meshing geometry of highconlacl-ratio gears. Contact ratio, 2.226 .

resulting contact ratios and toolh stiffnesses were calculated by the methods presented in Cornell (1980/1981) and Lin et al. (1988). In this study the contact ratio ranged from 1.20 to 2.40 . This range encompasses both low-contact-ratio and high-contact-ratio gears. For this study the gears had no profile modification.

The meshing geometry and corresponding gear mesh stiffness for a typical LCRG are illustrated in Fig. 1. Similar illustrations for HCRG are given in Fig. 2. According to the literature (Harris, 1958; Kasuba and Evans, 1981; Kubo and Kiyono, 1980; and Sato et al., 1981), variation of the meshing stiffness is a major source of vibration excitation in gears. Changing the contact ratio, as illustrated in these figures, will have an important effect on the meshing stiffness and therefore on the gear dynamics.

\section{Cornputer Simulation Model}

The computer program DANST employs four torsional degrees of freedom. These degrees of freedom (depicted in Fig. 3) represent the input (motor), the two gears, and the output (load). The computer model, which simulates the dynamic behavior of the transmission, assumes that the motor, the load, and the two gears act as mass inertias and that the shafts and the gear teeth act as springs of a rotational system (Kasuba and Evans, 1981; and Lin et al., 1988). The motion of the system can therefore be expressed by the following set of differential equations:
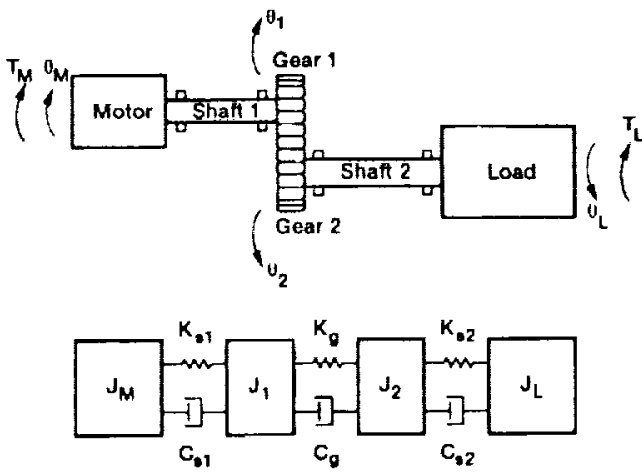

Fig. 3.-Simple gear transmission model.

$$
\begin{aligned}
& J_{u} \bar{\theta}_{u}+C_{s 1}\left(\dot{\theta}_{u}-\dot{\theta}_{1}\right)+K_{\mu 1}\left(\theta_{u}-\theta_{1}\right)=T_{u} \\
& J_{1} \tilde{\theta}_{1}+C_{s 1}\left(\dot{\theta}_{1}-\dot{\theta}_{\mu}\right)+K_{s 1}\left(\theta_{1}-\theta_{\mu}\right)+C_{8}(t)\left[R_{b} 1 \dot{\theta}_{1}-R_{b} 2 \dot{\theta}_{2}\right] \\
& +K_{s}(t)\left[R_{b 1}\left(R_{b l} \theta_{1}-R_{b 2} \theta_{2}\right)\right]=T_{\Omega}(t) \\
& J_{2} \ddot{\theta}_{2}+C_{2}\left(\dot{\theta}_{2}-\dot{\theta}_{L}\right)+K z\left(\theta_{2}-\theta_{\nu}\right)+C_{g}(t)\left[R_{b 2} \dot{\theta}_{2}-R_{b 1} \dot{\theta}_{1}\right] \\
& +K_{f}(t)\left[R_{b} 2\left(R_{b 2} \theta_{2}-R_{b 1} \theta_{1}\right)\right]=-T_{\beta 2}(t)
\end{aligned}
$$

$$
J_{L} \ddot{\theta}_{L}+C_{B}\left(\dot{\theta}_{L}-\dot{\theta}_{2}\right)+K_{B}\left(\theta_{L}-\theta_{2}\right)=-T_{L}
$$

where

$\theta_{w} \theta_{1}, \theta_{2}, \theta_{L} \quad$ angular rotation of motor, gears, and load (Overdots indicate time differentiation.)

$J_{M} J_{1}, J_{2}, J_{L} \quad$ mass moments of inertia of motor, gears, and load

$C_{s 1}, C_{n}, C_{s}(t) \quad$ damping factor of shafts and gear mesh

$\boldsymbol{K}_{a 1}, \boldsymbol{K}_{\infty}, \boldsymbol{K}_{g}(t) \quad$ stiffness of shafts and meshing gear teeth

$\boldsymbol{R}_{b 1}, \boldsymbol{R}_{b 2} \quad$ base radii of gears

$T_{w} T_{n}, T_{R}, T_{L} \quad$ torque from motor, gear friction, and load time

For the dynamic analysis the DANST code obtains the system natural frequencies (or resonance speeds) by using an average value of gear meshing stiffness to solve the undamped system equations of motion. This average value is computed as the sum of many discrete values of tooth meshing stiffness during the mesh cycle divided by the number of mesh positions (in this case 121 ) in the cycle (Lin et al., 1988).

The differential equations of motion are solved in DANST by a fourth-order Runge-Kutta Nystrom method (Kreyszig, 1972). This method employs a linearized iterative procedure that involves dividing the mesh period into many equal intervals. Initjal angular displacements are obtained by preloading the input shaft with the nominal torque carried by the system. Initial angular speeds are taken from the nominal system operating speed. For steady-state operation the dynamic motions of the system can be found from this iterative procedure. The method is described in detail in Lin et al. (1988). 


\section{Dynamic Tooth Load and Load Factor}

The dynamic tooth load at contact point $t$ is the product of the relative gear tooth displacements $\left(\boldsymbol{R}_{b 1} \boldsymbol{\theta}_{1}-\boldsymbol{R}_{b 2} \boldsymbol{\theta}_{2}\right)$ and the corresponding meshing stiffness plus the product of the velocities $\left(\boldsymbol{R}_{b 1} \dot{\theta}_{1}-\boldsymbol{R}_{b 3} \hat{\theta}_{2}\right)$ with the damping. If gear 1 is the driving gear and $\delta$ is the backlash, the following conditions can occur:

Case (1): $\left(\boldsymbol{R}_{b 1} \boldsymbol{\theta}_{1}-\boldsymbol{R}_{b_{2}} \boldsymbol{\theta}_{2}\right)>0$. This is the normal operating case. The dynamic tooth load $W_{d}$ at point $i$ is then

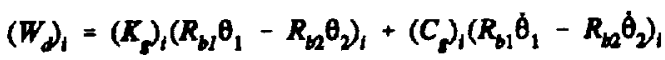

Case (2): $\left(\boldsymbol{R}_{b 1} \boldsymbol{\theta}_{1}-\boldsymbol{R}_{b 2} \boldsymbol{\theta}_{2}\right) \leq 0$ and $\left|\boldsymbol{R}_{b 1} \boldsymbol{\theta}_{1}-\boldsymbol{R}_{b 2} \boldsymbol{\theta}_{2}\right|_{i} \leq 8$. In this case the gears will separate and the contact between them will be lost. Hence,

$$
\left(W_{D_{1}}=0\right.
$$

Case (3): $\quad\left(\boldsymbol{R}_{b 1} \boldsymbol{\theta}_{1}-\boldsymbol{R}_{b 2} \theta_{2}\right)<0$ and $\left|\boldsymbol{R}_{b 1} \boldsymbol{\theta}_{1}-\boldsymbol{R}_{b 2} \boldsymbol{\theta}_{2}\right|_{l}>\mathbf{8}$. In this case gear 2 will collide with gear 1 on the back side; then,

$$
\left(W_{d}\right)_{1}=\left(\boldsymbol{R}_{p}\right)_{1}\left(R_{b 2} \theta_{2}-R_{b 1} \theta_{1}\right)_{l}+\left(C_{p}\right)_{1}\left(R_{b 2} \dot{\theta}_{2}-R_{b 1} \hat{\theta}_{1}\right)_{i}
$$

After the gear dynamic load has been calculated, the dynamic load factor can be determined by comparing the maximum magnitude of the gear dynamic load during mesh to that of the static applied load. This comparison indicates the instantaneous increase of gear tooth load over the nominal static load and is generally used for demonstrating the dynamic action of a gear transmission.

Harris (1958) and Ichimaru and Hirano (1974) found that the dynamic load factor tends to be higher for lightly loaded gears than for heavily loaded gears. Because the actual dynamic tooth load is the product of nominal applied load and dynamic load factor, it is possible for a lightly loaded gear with a high dynamic factor to have either a lower or higher dynamic load than a heavily loaded gear with a low dynamic load factor.

For this investigation of the contact ratio effect on the dynamics of spur gear transmissions, a constant design torque of $425 \mathrm{~N}-\mathrm{m}(3760 \mathrm{lb}-\mathrm{ft})$ is applied to the system. The constant input torque eliminated confusion due to differences between the dynamic load factor and the actual dynamic tooth load.

\section{RESULTS AND DISCUSSION}

DANST solves the equations of motion as described previously to obtain the dynamic load, the dynamic load factor, the stress, etc. For the investigation reported herein the dynamic load factor was computed over the speed range 1000 to $14000 \mathrm{rpm}$. The results are presented as "speed sweeps" comparing the dynamic load factor for various gear contact ratios. All comparisons were made at a constant torque.

Figure 4 compares three different LCRG transmissions with contact ratios (CR) of $1.668,1.754$, and 1.868. Although the dynamic curves exhibit similar trends, their magnitudes are significantly different, particularly near the system resonant speed (about $9000 \mathrm{rpm}$ ) and at certain submultiples (particularly $1 / 2,1 / 3$, and $1 / 6$ ) of the resonant speed. Note that as the contact ratio changed, the system natural frequency varied because of the changing average stiffness.

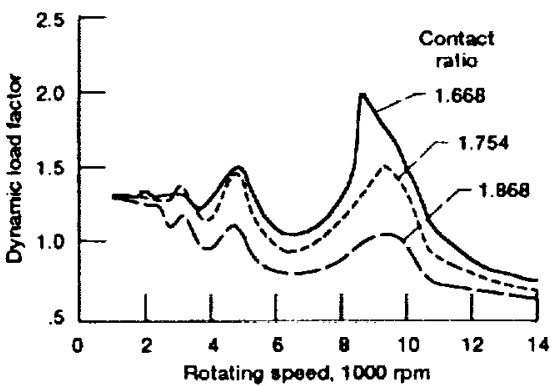

Fig. 4-Dynamic load lactors for low - contact-ratio

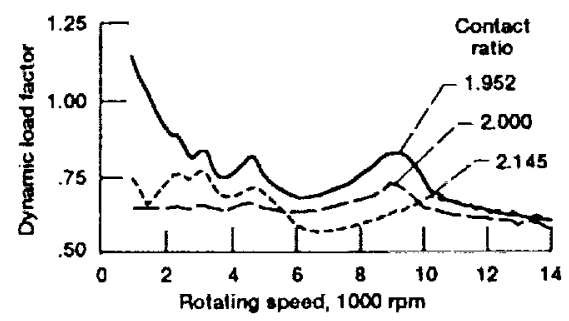

Fig. 5. -Dynamic load factors for transition from lowcontact-ratio gears to high-contact-ratio gears

For LCRG the dynamic load factor generally decreased as the gear contact ratio increased. This phenomenon was most prominent at the main resonant speed, near $9000 \mathrm{rpm}$, and at one-half of this resonant speed. The gears with the highest contact ratio ( $C R=1.868$ ) had lower dynamic load at higher speeds. We believe that this effect is due to the very narrow band of single-tooth contact being passed so quickly during gear rotation that the system could not respond until after the excitation has passed. The highspeed behavior of LCRG with CR close to 2.0 was similar to that of high-contact-ratio gears.

A comparison of the dynamics of "transition" gears $(\mathrm{CR}=1.952,2.000$, and 2.145$)$ is shown in Fig. 5 . The dynamic curve for $\mathrm{CR}=1.952$ shows a trend similar to that for $\mathrm{CR}=1.868$ in the previous figure. At a CR of exactly 2 there will be almost no variation of the meshing stiffness during tooth contact. As a result the dynamic response will be very gentle, even at resonant speeds. At $\mathrm{CR}=\mathbf{2 . 1 4 5}$ excitation due to the variation in meshing stiffness between double- and triple-tooth contact produced some dynamic effect at lower speeds (below $5000 \mathrm{rpm}$ ). As speed increased beyond $5000 \mathrm{rpm}$, the effect of the stiffness variation diminished, as shown in the figure.

Figure 6 compares the dynamic load factors for HCRG $(C R=2.226,2.306$, and 2.412$)$. The dynamic load factor curves for HCRG show different trends at the resonant speed of the gear system (at approximately $9300 \mathrm{rpm}$ ) and its submultiples (at about 4650 and $3100 \mathrm{rpm}$ ). The gears with the lowest contact ratio (2.226) had the highest dynamic load at submultiple speeds, but the

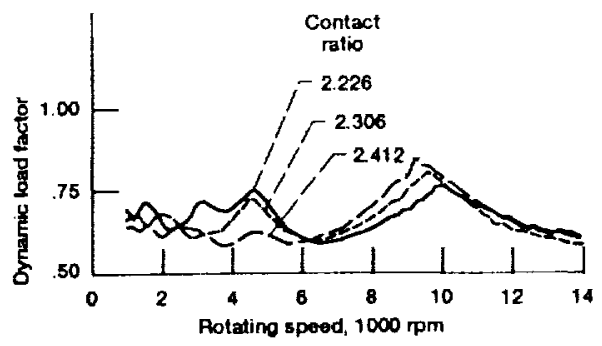

Fig. 6-Dynamic load factors for high-contact-ratio goars. 


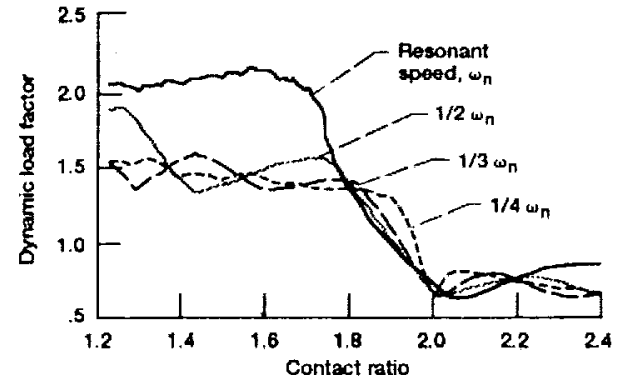

Fig. 7. Efloct of contact ratio on dynamic load factor at syatem resonant speed and submultiplos.

trend reversed at the resonant speed, where the gears with the highest contact ratio experienced the highest loar. We believe that this phenomenon is due to excitation from the transition between double- and triple-tooth contact. For gears with $\mathrm{CR}=2.226$ the triple-tooth-contact region was shorter than that of the two cases with higher contact ratios. The excitation due to the change in meshing stiffness acted like an short-duration impulse, which is more effective at lower speeds than at higher speeds.

Contact ratio effects on the dynamic load at the resonant speed (designated $\omega_{n}$ ) and at certain submultiples $(1 / 2,1 / 3$, and $1 / 4$ of $\left.\omega_{n}\right)$ are illustrated in Fig. 7 . Because the gear mesh stiffness varied with the contact ratio, the resonant speed, which corresponds to the natural frequency of the system, also varied with the contact ratio. (For the data shown in Fig. 7 , the resonant speed ranged from about 8400 to $10000 \mathrm{rpm}$.) Each curve in Fig. 7 was produced from 200 data points representing the different contact ratios. The dynamic load factors were found from speed sweeps like those shown in Figs. 4 to 6.

The data in Fig. 7 may be grouped into three zones: In zone 1 (CR $\$ 1.7$ ) the dynamic load factor at resonant speed was nearly constant at approximately 2.0. For the submultiples of $\omega_{n}$ the dynamic load factor oscillated around a level approximately 25 percent less than the value of $\omega_{n}$. In zone 2 (a transition zone where $C R \approx 1.7$ to 2.0 ) the dynamic load factor dropped rapidly as the contact ratio increased, reaching a minimum of 0.64 at $\mathrm{CR}=2.0$. The dynamic load for $\omega_{\mathrm{n}}$ fell off first, and then the smaller multiples of $\omega_{n}$ fell off at a higher value of CR. Finally, in zone $3(\mathrm{CR}>2.0)$ the dynamic load factor oscillated between 0.64 and approximately 0.8 . As a general trend HCRG have smaller dynamic effect than LCRG.

Figure 7 shows that increasing the contact ratio does not always reduce the dynamic load. For gears that operate over a wide speed range a contact ratio very close to 2.0 is a good choice. For gears that operate at low speeds (less than about 70 percent of $\omega_{n}$ ), contact ratios of 2.0 or above are good choices for minimizing dynamic load.

Because both speed and contact ratio play an important role in determining the dynamic load of a gear system, their combined effects were investigated. Figure $8(a)$ is a three-dimensional representation of the dynamic load factor as influenced by the contact ratio and the rotating speed (in the speed range 1000 to $14000 \mathrm{rpm})$. Figure $8(\mathrm{~b})$ is a contour diagram of the same data. This is a good tool for locating the exact position of the dynamic peaks and valleys. Gears with minimum dynamic load will be located in the valleys of this figure.

$$
\text { this }
$$

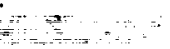

As the figure shows, the dynamic load factors were generally significantly higher for LCRG than for HCRG. Dynamic peaks were found at the gear system natural frequency and its submultiples. However, near $C R=2$ the dynamic effects were minimal.

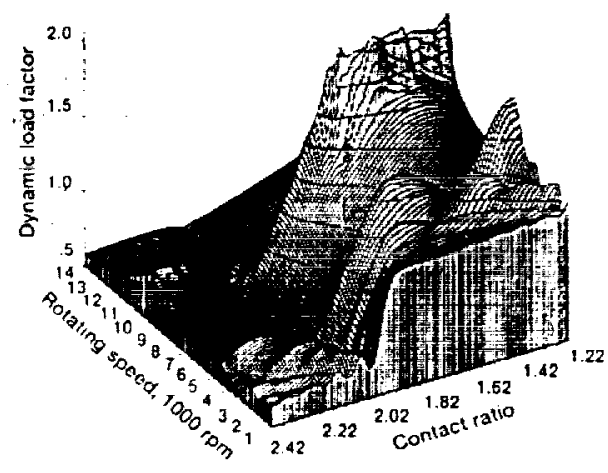

(a) Three-dimensional representation.

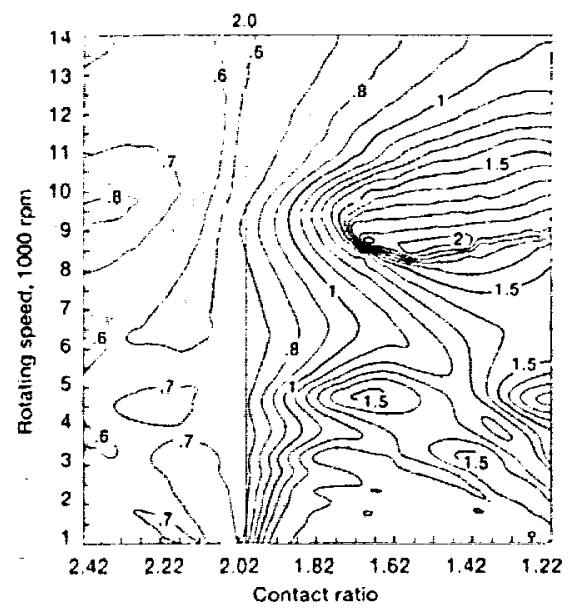

(b) Contour diagram.

Fig. 8. -Effect of contact ratio and rotating speed on gear dymamic load factor.

For some applications it may be necessary to design a system with contact ratios other than the desired value of 2.0. Moreover, the contact ratio of a gear system may be altered by variations in load which can cause shaft deflections that change the contact ratio from the theoretical value. Figure 8 shows the effect of such changes for the gear system analyzed in this paper. The DANST code can be used to generate the data required for similar figures for other gear systems.

A design for minimum dynamic load can be determined by selecting a possible contact ratio from Fig. 8, taking into consideration the intended operating speeds. As an example, for lowspeed operation (up to $8000 \mathrm{rpm}$ ) an HCRG with a contact ratio of approximately 2.0 or 2.4 will minimize the dynamic effects. Other $C R$ values may create undesirable higher dynamic loads.

Note that above the resonant spced of the gear system the contact ratio effect on gear dynamics is diminished. This phenomenon is more apparent in LCRG than in HCRG. Very low contact ratios (CR < 1.30) produce high dynamic loads throughout most of the speed range and therefore should be avoided.

\section{CONCLUSIONS}

The effect of the contact ratio on spur gear dynamic load was investigated. Contact ratios ranging from 1.20 to 2.40 were obtained by varying the length of the tooth addendum. Other parameters that can affect the contact ratio were held constant. The following conclusions were drawn from this investigation: 
1. Dynamic load is significantly lower for high-contact-ratio gears than for low-contact-ratio gears.

2. Over a wide range of operating speeds a contact ratio close to 2.0 minimizes dynamic load.

3. For low-contact-ratio gears in general, increasing the contact ratio reduces the dynamic load. The most significant effect occurs at contact ratios of 1.80 and higher.

4. For high-contact-ratio gears the best value of the contact ratio depends on the operating speed. Increasing the contact ratio does not always reduce the dynamic load.

5. At speeds much greater than the natural resonant speed of the gear system, the contact ratio has much less effect on the dynamic load.

\section{REFERENCES}

Benton, M., and Seireg, A., 1981, "Factors Influencing Instability and Resonances in Geared Systems," Journal of Mechanical Design, Vol. 103, No. 2, pp. 372-378.

Cornell, R.W., 1981, "Compliance and Stress Sensitivity of Spur Gear Teeth," Journal of Mechanical Design, Vol. 103, No. 2, pp. 447-459. (Also, ASME Paper 80-C2/DET-24, 1980.)

Harris, S.L., 1958, "Dynamic Loads on the Teeth of Spur Gears," Proceedings of the Institution of Mechanical Engineers, Vol. 172, No. 2, pp. 87-112.

Ichimaru, K., and Hirano, F., 1974, "Dynamic Behavior of Heavy-Loaded Spur Gears," Journal of Engineering for Industry, Vol. 96, No. 2, pp. 373-381.

Kasuba, R., and Evans, J.W., 1981, "An Extended Model for Determining Dynamic Loads in Spur Gearing," Journal of Mechanical Design, Vol. 103, No. 2, pp. 398-409.

Kreyszig, E., 1972, Advanced Engineering Mathematics, Third Edition, John Wiley \& Sons, New York, pp. 668-670.
Kubo, A., and Kiyono, S, 1980, "Vibrational Excitation of Cylindrical Involute Gears Due to Tooth Form Error," JSME Bulletin, Vol. 23, No. 183, pp. 1536-1543.

Lin, H.H., Oswald, F.B., and Townsend, D.P., 1989, "Profile Modification to Minimize Spur Gear Dynamic Loading," International Power Transmission and Gearing Conference 5th: New Technologies for Power Transmissions for the 90's, ASME, New York, Vol. 1, pp. 455-465.

Lin, H.H., Huston, R.L., and Coy, J.J., 1988, "On Dynamic Loads in Parallel Shaft Transmissions: Part I - Modeling and Analysis," Journal of Mechanisms, Transmissions and Automation in Design, Vol. 110, No. 2, pp. 221-225.

Mizutani, H., and Yuruzume, I., 1981, "Noise and Vibration of High Speed Spur Gears," Proceedings of the International Symposium on Gearing and Power Transmissions, JSME, Tokyo, Japan, Paper C-5, pp. 25-29.

Oswald, Fred B., Rebbechi, Brian, Zakrajsek, James J., and Townsend, Dennis P., 1991, "Comparison of Analysis and Experiment for Dynamics of Low-Contact-Ratio Spur Gears," NASA TM-103232.

Sato, T., Umezawa, K., and Ishikawa, J., 1981, "Influence of Various Gear Errors on Rotational Vibration," Proceedings of the International Symposium on Gearing and Power Transmissions, JSME, Tokyo, Japan, Paper C-10, pp. 55-60.

Sato, T., Umezawa, K., and Ishikawa, J., 1983, "Effects of Contact Ratio and Profile Correction on Gear Rotational Vibration," JSME Bulletin, Vol. 26, No. 221, pp. 2010-2016.

Staph, H.E., 1976, “A Parametric Analysis of High-Contact-Ratio Spur Gears," ASLE Transactions, Vol. 19, No. 3, pp. 201-215.

Terauchi, Y., Nadano, H., and Nohara, M., 1982, "On the Effect of the Tooth Profile Modification on the Dynamic Load and the Sound Level of the Spur Gears," JSME Bulletin, Vol. 25, No. 207, pp. 1474-1481. 
Public reporting burden for this collection of iniormation is estimated to average 1 hour per response, including the time for reviewing instructions, searching existing data sources, gathering and maintaining the data needed, and completing and reviewing the collection of information. Send comments regarding this burden estimate or any other aspect of this collection of information, including suggestions for reducing this burden, to Washington Headquarters Services, Directorate for information Operations and Reports, 1215 Jefferson Davis Highway, Suite 1204, Arlington, VA 22202-4302, and to the Office of Management and Budget, Paperwork Reduction Project (0704-0188). Washington, DC 20503.

\section{\begin{tabular}{l|l|l}
\hline 1. AGENCY USE ONLY (Leave blank) & 2. REPORT DATE - & 3. REPOAT TYPE AND DATES COVERED
\end{tabular}}

\begin{tabular}{l|l|l} 
& 1992 & Technical Memorandum \\
\hline
\end{tabular}

\section{TITLE AND SUBTITLE}

Effect of Contact Ratio on Spur Gear Dynamic Load

6. AUTHOR(S)

Chuen-Huei Liou, Hsiang Hsi Lin, Fred B. Oswald, and Dennis P. Townsend

\section{FUNDING NUMBERS}

WU-505-63-36

1L162211A47A

\section{PERFORMING ORGANIZATION NAME(S) AND ADDRESS(ES)}

NASA Lewis Research Center

Cleveland, Ohio 44135-3191

and

Propulsion Directorate

U.S. Army Aviation Systems Command

Cleveland, Ohio 44135-3191

9. SPONSORING/MONITORING AGENCY NAMES(S) AND ADDRESS(ES)

National Aeronautics and Space Administration

Washington, D.C. 20546-0001

and

U.S. Army Aviation Systems Command

St. Louis, Mo. 63120-1798
8. PERFORMING ORGANIZATION

REPORT NUMBER

E-6942

10. SPONSORING/MONITORING AGENCY REPORT NUMBER

NASA TM-105606

AVSCOM TR-91-C-025

11. SUPPLEMENTARY NOTES

Prepared for the Sixth International Power Transmission and Gearing Conference sponsored by the American Society of Mechanical Engineers, Phoenix, Arizona, September 13-16, 1992. Chuen-Huei Liou and Hsiang Hsi Lin, Memphis State University, Memphis, Tennessee, 38152; Fred B. Oswald and Dennis P. Townsend, NASA Lewis Research Center. Responsible person, Fred B. Oswald, (216) 433-3957.

12a. DISTRIBUTION/AVAILABILITY STATEMENT

12b. DISTAIBUTION CODE

Unclassified - Unlimited

Subject Category 37

\section{ABSTRACT (Maximum 200 words)}

This paper presents a computer simulation showing how the gear contact ratio affects the dynamic load on a spur gear transmission. The contact ratio can be affected by the tooth addendum, the pressure angle, the tooth size (diametral pitch), and the center distance. The analysis presented in this paper was performed by using the NASA gear dynamics code DANST. In the analysis the contact ratio was varied over the range 1.20 to 2.40 by changing the length of the tooth addendum. In order to simplify the analysis, other parameters related to contact ratio were held constant. The contact ratio was found to have a significant influence on gear dynamics. Over a wide range of operating speeds a contact ratio close to 2.0 minimized dynamic load. For low-contact-ratio gears (contact ratio less than 2.0), increasing the contact ratio reduced the gear dynamic load. For high-contact-ratio gears (contact ratio equal to or greater than 2.0), the selection of contact ratio should take into consideration the intended operating speeds. In general, high-contact-ratio gears minimized dynamic load better than low-contact-ratio gears.

14. SUBJECT TERMS

High contact ratio gears; Spur gears; Contact ratio; Dynamic load

17. SECURITY CLASSIFICATION
OF REPORT
Unclassified

NSN 7540-01-280-5500
18. SECURITY CLASSIFICATION OF THIS PAGE

Unclassified
19. SECURITY CLASSIFICATION OF ABSTRACT

Unclassified 